\title{
Precision in Diagnosing and Classifying COPD: Comparison of Historical Height with Current Height and Arm Span to Predict FEV 1
}

\author{
Khalid Ansari ${ }^{*},{ }^{,}$, Niall Keaney ${ }^{2}$, Monica Price ${ }^{1}$, Joan Munby ${ }^{1}$, Andrea Kay ${ }^{2}$, \\ Ian Taylor ${ }^{2}$, Kathryn King ${ }^{1}$. \\ ${ }^{I}$ Faculty of Pharmacy, Health and Wellbeing, University of Sunderland, Sunderland, England, UK \\ ${ }^{2}$ Sunderland Royal Hospital, Sunderland, NE, England, UK
}

\begin{abstract}
Background: Measured reductions in lung function, as a result of COPD, use a measured current value and make comparisons to a determined 'normal' value arrived at using a regression equation based upon a patients height. Osteoporosis is a recognised co-morbidity in patients with chronic obstructive pulmonary disease (COPD) and may cause excessive height loss resulting in the 'normal' values and disease progression being under-estimated.
\end{abstract}

Purpose: The aim of the study was to examine the height variation in a cohort of COPD patients and controls over a 7-8 years period and evaluate its impact on estimates of lung function and hence COPD progression.

Methods: In 1999-2002 we studied a cohort of primary care patients in Sunderland, UK with and without COPD and reexamined 104 (56 male) during 2007-2009. We calculated $\mathrm{FEV}_{1} \%$ predicted for actual and estimated height (armspan/1.03 and armspan/1.01 in males and females respectively).

Results: In 1999-2002 the subjects were aged 62.6 \pm 9.4 years, BMI was $26.4 \pm 4.7 \mathrm{~kg} / \mathrm{m}^{2}$, predicted $\mathrm{FEV}_{1}$ was $59.0 \pm 16.0$, and mean actual height was $167.3 \pm 8.9 \mathrm{~cm}$. The actual height changed significantly $(\mathrm{p}<0.001)$ by $2 \mathrm{cms}$ over time in both genders. Whilst the overall classifications of the cohort did not change significantly when armspan was used to determine height and hence normal lung volume, individual cases did move to a classification of higher severity.

Conclusions: The study suggests that current measured height may underestimate the degree of impairment of FEV1 and hence progression of COPD. The use of height, derived from armspan, may give a more accurate measure of 'normal' lung volumes and hence the degree of impairment.

Keywords: Chronic obstructive pulmonary disease, historical height, osteoporosis.

\section{INTRODUCTION}

The diagnosis of COPD, chronic obstructive pulmonary disease, currently depends on demonstrating limitations of airflow, using spirometry, the gold standard method for obstructive disease of the airways. A diagnosis of COPD is normally made if the ratio of the forced expiratory volume in the first second $\left(\mathrm{FEV}_{1}\right)$ to forced vital capacity $(\mathrm{FVC})$ is below 0.70 (Global Initiative for Obstructive Lung Disease GOLD, 2010) [1].

Impairment of $\mathrm{FEV}_{1}$ has also been utilised to classify the severity of airflow obstruction for COPD, in a range of guidelines, including those recommended by the National Institute of Clinical Excellence (NICE) in the UK [2]. Impairment of $\mathrm{FEV}_{1}$ is determined by making reference to predicted (normal) volumes. As spirometric values are dependant on the size of the lungs, which is in turn directly related to height, gender, age and ethnic origin [3] the predicted normal value for lung capacity is determined using measures for these variables. One regression equation that is

*Address correspondence to this author at the Science Complex, University of Sunderland, SR1 3SD, UK; Fax: 00-44-1915152257;

E-mails: khalidansari111@hotmail.com, khalid.ansari@sunderland.ac.uk commonly used is that proposed in the European Respiratory Society (ERS) guidelines [4].

For Males: PREDICTED FEV1 $=(4.30 \mathrm{x}$ height $)-(0.029 \mathrm{x}$ age - 2.49)

For Females: PREDICTED FEV1 $=(3.95 \mathrm{x}$ height $)-(0.025$ $\mathrm{x}$ age - 2.60)

However, some of these variables, including height may be affected by other factors including osteoporosis and this will confound the interpretation of comparisons made to a predicted normal value for lung capacity that has been determined based upon a patients' height.

In terms of height Sorkin et al. [5] found that in healthy Caucasians a longitudinal decline in height, with aging, becomes apparent from the age of 40 years. An initial rate of decline of $1 \mathrm{~cm}$ per year accelerates after the age of 60 years with women losing more height than men. However, Capderou et al., (2011) [6] in a large single centre study comparing historic height with current measured height concluded that significant height loss becomes important after the age of 70. In patients with COPD height loss may occur at an earlier age due to the high prevalence of osteoporosis in smokers [7, 8]. Osteoporosis is also a recognised complication of regular treatment with oral 
corticosteroids which are often used to treat exacerbations in COPD $[9,10]$. Although there is little systemic absorption of inhaled corticosteroids some concern exists that they might increase the risk of osteoporosis $[11,12]$. Hence height may not be the most accurate measure to use, to determine predicted 'normal' lung volume in patients suffering from COPD. Using current height to determine the predicted values of $\mathrm{FEV}_{1}$ may mean that the degree of impairment of $\mathrm{FEV}_{1}$ is subject to confounding particularly in an elderly population.

This paper has therefore considered the use of armspan as an alternative measure for the estimation of height and in the prediction of 'normal' lung volume. Armspan is quick and easy to measure, is low cost and a useful alternative when standing height is difficult to measure such as in patients with disabilities who cannot stand, bedridden patients and those with bony deformities [7-13].

The research was carried out using a cohort of COPD patients recruited in a primary care setting in the North East of England. Members of the cohort were first examined in 1999-2002. The second examination occurred in 2007-2008.

\section{METHODS}

In the study reported here the cohort was first evaluated between September 1999 and December 2002, when patients with suspected COPD, attending primary care asthma clinics, were identified by performing spirometry according to the British Thoracic Society guidelines (BTS) [14].

Patients were classified as having COPD utilising the absolute post-bronchodilator $\mathrm{FEV}_{1} / \mathrm{FVC}$ ratio $\leq 0.7$.
Exclusion criteria were: $\mathrm{FEV}_{1} / \mathrm{FVC}>0.7$; age $<40$ years and a clear diagnosis of asthma based on BTS criteria of an increment over baseline $\mathrm{FEV}_{1}$ of more than $15 \%$ and more than $200 \mathrm{mls}$ with the bronchodilator and patient with any obvious bony deformity that may alter armspan or height measurements.

Patients in the non COPD control group were classified as those with $\mathrm{FEV}_{1} \%$ predicted values of $>80 \%$ and with no symptomatic evidence of obstructive disease such as cough and shortness of breath.

Height was recorded using a single stadiometer without shoes and arm span was measured. Armspan is defined as the maximum distance from the tip of the middle finger of one hand to the tip of the same finger of the other hand with outstretched arms and the subject standing erect. Spirometry (Vitalograph 2120); before and after bronchodilatation was also undertaken.

$\mathrm{FEV}_{1} \%$ predicted was determined for measured height and for estimated height based upon armspan (armspan/1.03 and armspan/1.01 in males and females respectively) [15].

In 2007-2008 survivors from this cohort were asked to attend for review.

Sunderland Local Research Ethics Committee approved this study.

\section{Statistical Analysis}

The non-parametric Spearman correlation coefficient was calculated to describe the relationships between the continuous variables that were not normally distributed. A

Table 1. Demographics of the Cohort According to Gender in 1999-2002

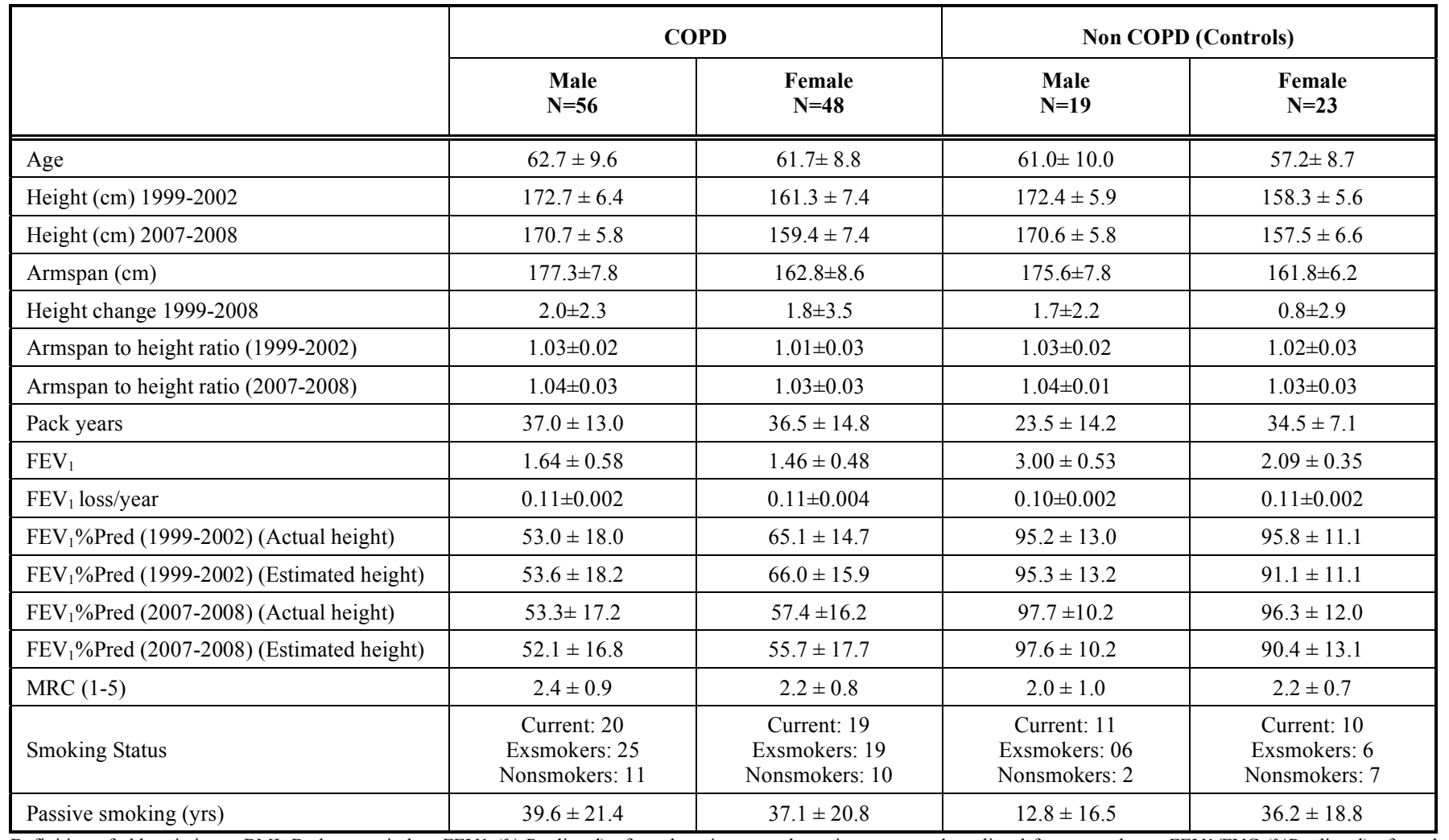

Definition of abbreviations= BMI=Body mass index; FEV1 (\% Predicted $)=$ forced expiratory volume in one second predicted for age and sex; FEV1/FVC $(\%$ Predicted $)=$ forced expiratory ratio (as predicted); BOD=BMI, airway Obstruction, MRC Dyspnoea score, $\mathrm{M}=$ metres; $\mathrm{L}=$ litres; $\mathrm{MRC}=\mathrm{Medical}$ Research Council Dyspnoea Score. 
two sample $t$ test was used to measure the difference of height and $\mathrm{FEV}_{1}$ predicted values in males and females and paired $t$ test was used to explore the height loss measured 7-8 years apart. ANOVA was employed to examine the distribution of height loss in different age range quartiles.

A chi square test was used to evaluate the significance of the movement of individuals to a different stage classification of COPD (GOLD) dependent on whether their 'normal' lung capacity was determined from their measured height or their armspan.

The data analysis was carried out using SPSS 17.0.

\section{RESULTS}

From the survivors of the original cohort 104 patients with COPD and 42 without COPD attended for review in 2007-2008, Table 1 presents their demographic characteristics.

All members of the COPD cohort showed a significant loss in measured height, mean $2 \mathrm{~cm}$ from 1999-2002 to 2007-2008. This can also be seen in Fig. (1) however this difference in height is not shown when height is determined using armspan.

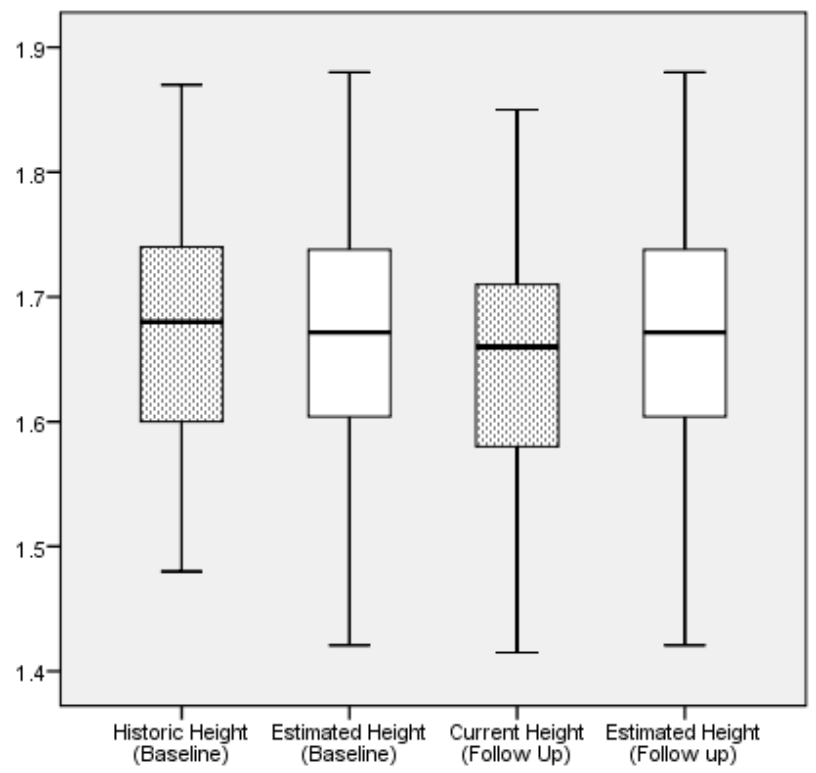

Fig. (1). Height variation over time at baseline and followup in study Subjects (All measuremtns were recorded in meters).

Fig. (2) shows that for the cohort, loss of height, increased with age. This loss of height with age is also reflected in the change in armspan to height ratio (Fig. 3) although the results here are more variable.

$\mathrm{FEV}_{1} \%$ predicted in $2007 / 8$ was significantly $(\mathrm{p}<0.001)$ lower when using height determined from armspan - 53.3 $\pm 17.2 \%$ against $52.1 \pm 16.8 \%$ in males and $57.5 \pm 16.1$ vs $55.7 \pm 17.7$ in females within the COPD group. However, this difference was only found with the female members of the control cohort.

Table 2 shows the distribution of patients classified according to GOLD criteria in both 19992-2002 and 20072008. There was no significant movement between stages as a result of recalculating $\mathrm{FEV}_{1} \%$ predicted from height estimated from armspan. Whilst this would suggest that there is no need to change the management plan and/or prescriptions for the group overall there will be a significant impact upon those individuals whose classification does change.

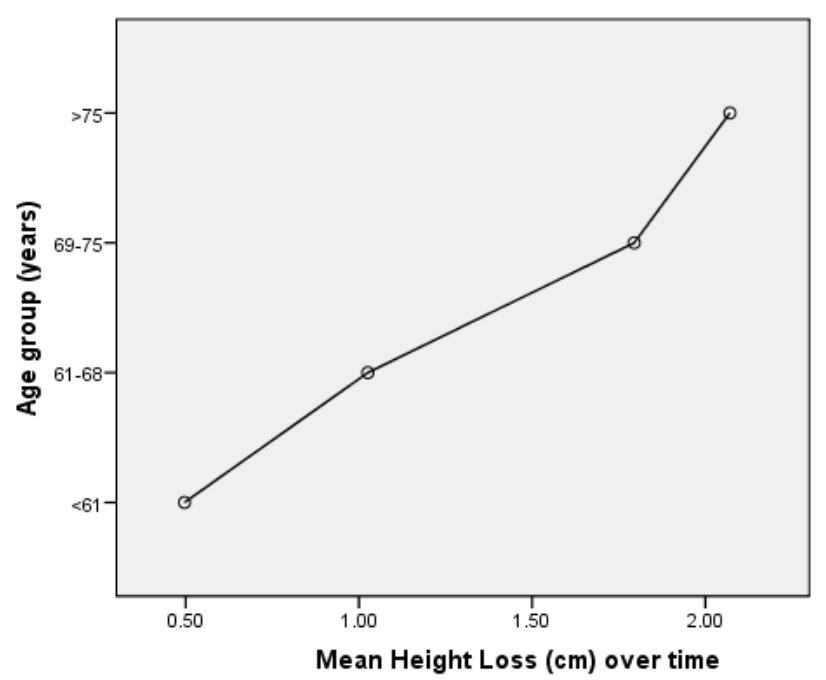

Fig. (2). Mean Measured Height Loss overtime (1999/20022007/2008) in different age groups.

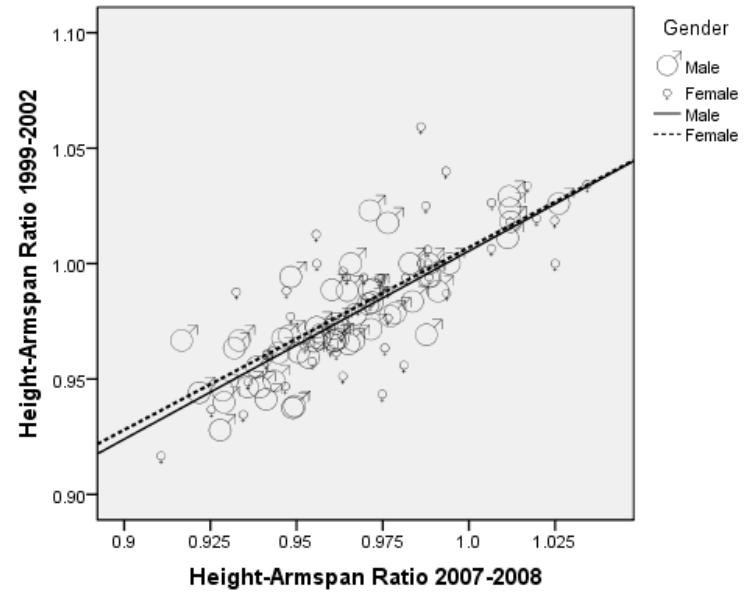

Fig. (3). Relationship of Height -Armspan ratio overtime $\left(\mathrm{R}^{2}=0.639\right.$ in men and 0.575 in women).

\section{DISCUSSION}

The accurate classification of COPD is important in that strategies need to be developed for the management of these patients. Therefore if impairment of $\mathrm{FEV}_{1}$ is to be used to classify the stage of disease progression there is a need for accurate predictions to be made for normal lung volumes. These are currently calculated using a regression equation in which current height is one of the variables. However, current height can be confounded by a number of other factors including osteoporosis.

In this study we have shown that patients both those with confirmed COPD and the controls exhibit a significant reduction in mean height of $2 \mathrm{~cm}$ over a median period of observation of about 8 years. This variation of height in turn 
Table 2. Influence of Calculating FEV1\% Predicted from Actual Height and Estimated Height on Severity Classification in COPD Patients

\begin{tabular}{|c|c|c|c|}
\hline \multicolumn{4}{|c|}{ GOLD Classification } \\
\hline 1999-2002 & $\begin{array}{c}\text { Measured FEV }_{1} \\
\text { (Measured Height) }\end{array}$ & $\begin{array}{l}\text { Estimated FEV } \% \\
\text { (Calculated Height) }\end{array}$ & p Value \\
\hline Stage I & $\mathrm{n}=04$ & $\mathrm{n}=11$ & \multirow{4}{*}{ NS } \\
\hline Stage II & $\mathrm{n}=63$ & $\mathrm{n}=57$ & \\
\hline Stage III & $\mathrm{n}=25$ & $\mathrm{n}=24$ & \\
\hline Stage IV & $\mathrm{n}=08$ & $\mathrm{n}=08$ & \\
\hline \multicolumn{4}{|c|}{ GOLD Classification } \\
\hline 2007-2008 & $\begin{array}{l}\text { Measured FEV } \mathrm{F}_{1} \% \\
\text { (Measured Height) }\end{array}$ & $\begin{array}{l}\text { Estimated FEV } \text { F }_{1} \\
\text { (Calculated Height) }\end{array}$ & p Value \\
\hline Stage I & $\mathrm{n}=18$ & $\mathrm{n}=18$ & \multirow{4}{*}{ NS } \\
\hline Stage II & $\mathrm{n}=44$ & $\mathrm{n}=43$ & \\
\hline Stage III & $\mathrm{n}=33$ & $\mathrm{n}=32$ & \\
\hline Stage IV & $\mathrm{n}=05$ & $\mathrm{n}=7$ & \\
\hline
\end{tabular}

influences the predicted values of lung function, calculated to diagnose and classify the stages of COPD, thus underestimating the degree of severity in these patients. The reduction of standing height was more significant in female subjects suggestive of postmenopausal degenerative bony changes in women [16]. This is important as more females are now reporting with COPD.

It is an established problem that standing height loss occurs in elderly people and this is supported by our data (Fig. 2) which shows the mean height loss in different age groups over time. The underlying causes that are responsible for height reduction may include narrowing of vertebral space, age related vertebral fractures mainly due to osteoporosis, regular use of corticosteroid, female sex and lower body weight $[19,20]$.

Armspan has traditionally been used to estimate predicted lung volumes in pulmonary function laboratories especially when the subjects have a spinal deformity or are unable to stand. Armspan is correlated with height and the normal phenomenon is for armspan to slightly exceed height. A number of studies have examined this relationship $[13,17,18]$ and to estimate height from armspan measurements we chose ratios of 1.03 and 1.01 in men and women respectively as appropriate for a Caucasian population [13].

The information presented here shows that the calculated height measured by armspan is similar when estimated over time. However, the standing heights, measured using a stadiometer, are different at baseline and follow up (Fig. 1) indicating a possible under- estimation of normal lung volume if measured height is used to calculated $\mathrm{FEV}_{1}$. If this is the case the severity of COPD progression would be underestimated.

The conclusion that can be reached from these results is that the use of current height will mean that COPD progression is underestimated if measured height is used.
The use of armspan to determine height and hence normal lung volume will give a more accurate measure of the impairment of lung function and hence COPD progression.

There are some limitations to the study. The number of subjects both in the COPD and control groups is low however it was possible to demonstrate the impact of height loss across the cohort. Furthermore, historical heights were measured by the clinical staff in their local clinical settings in contrast to the work of Kjensli and colleagues [21]. Kjensli and colleagues reviewed whether height reduction influences interpretation of lung function in COPD patients. However they used the highest remembered height and compared this with current height. They showed that the spirometric values were influenced by height losses of greater than $5.9 \mathrm{~cm}$. This was especially true for those with a low FEV . $_{1}$

Future longitudinal studies are needed in order to validate our finding with a larger number of subjects.

\section{ACKNOWLEDGEMENTS}

The authors would like to thank all patients who participated in the study. The author would also like to thank Higher Education Commission, Pakistan and City Hospitals Sunderland, UK Research Grants to provide financial support to carry out this study.

\section{CONFLICT OF INTEREST}

None of the authors of the above manuscript (Dr. Khalid A. Ansari, Dr. N.P. Keaney, Dr. Monica Price, Dr. Joan Munby, Andrea Kay, Ian Taylor, and Dr. Kathryn King) has received fees or funds that might appear to affect their ability to present or review data objectively or serving as a speaker, consultant or an advisory board member in relation to the manuscript aims and objectives.

None of the authors of the above manuscript (Dr. Khalid A. Ansari, Dr. N.P. Keaney, Dr. Monica Price, Dr. Joan Munby, Andrea Kay, Ian Taylor, and Dr. Kathryn King) has any conflict of interest which may arise from being named as an author on the manuscript.

\section{REFERENCES}

[1] Global Initiative for Chronic Obstructive Lung Disease (GOLD). Global strategy for the diagnosis, management and prevention of chronic obstructive pulmonary disease. Bethesda (MA): Global Initiative for Chronic Obstructive Lung Disease 2010; p. 96.

[2] National Collaborating Centre for Chronic Conditions. Chronic obstructive pulmonary disease. National clinical guideline on management of chronic obstructive pulmonary disease in adults in primary and secondary care. Thorax 2004; 59 (Suppl 1): 1-232.

[3] Becklake MR. Concepts of normality applied to the measurement of lung function. Am J Med 1986; 80: 1158-63.

[4] Quanjer PH, Tammeling GJ, Cotes JE, et al. Lung volumes and forced ventilatory flows. Report Working Party Standardization of Lung Function Tests, European Community for Steel and Coal. Official Statement of the European Respiratory Society. Eur Respir J Suppl 1993; 16: 5-40.

[5] Sorkin JD, Muller DC, Andres R. Longitudinal change in the heights of men and women: consequential effects on body mass index. Epidemiol Rev 1999; 21: 247-60.

[6] Capderou A, Berkani M, Becquemin MH, et al. Reconsidering the arm span-height relationship in patients referred for spirometry. Eur Respir J 2011; 37: 157-63.

[7] Law MR, Hackshaw AK. A meta-analysis of cigarette smoking, bone mineral density and risk of hip fracture: recognition of a major effect. Br Med J 1997; 315: 841-6. 
[8] Cornuz J, Feskanich D, Willett W, Colditz G. Smoking, smoking cessation, and risk of hip fracture in women. Am J Med 1999; 106: 311-4.

[9] Barnes PJ, Celli B. R. Systemic manifestations and comorbidities of COPD. Eur Respir J 2009; 33: 1165-85.

[10] Fabbri LM, Luppi F, Beghe B, et al. Complex chronic comorbidities of COPD. Eur Respir J 2008; 31: 204-12.

[11] Jehle PM. Steroid-induced osteoporosis: how can it be avoided? Nephrol Dial Transplant 2003; 18: 861-4.

[12] Sewerynek E. Current indications for prevention and therapy of steroid-induced osteoporosis in men and women. Endokrynol Pol 2011; 62: 38-44

[13] Hepper NGG, Black LF, Fowler WS. Relationship of lung volume to height and arm span in normal subjects and in patients with spinal deformity. Am Rev Respir Dis 1965; 91: 356-62.

[14] The British Thoracic Society Standards of Care Committee. BTS Guidelines on the management of COPD. Thorax 1997; 52 (Suppl 5): S1-S28.
[15] Parker JM, Dillard TA, Phillips YY. Arm span-height relationships in patients referred for spirometry. Am J Respir Crit Care Med 1996; 154: 533-6.

[16] Demet Ofluoglu, Feyza Unlu, Gulseren Akyuz, et al. Relationship between arm span and height in postmenopausal osteoporotic women. Rheumatol Int 2008; 28: 737-41.

[17] Golshan M, Crapo RO, Amra B, et al. Armspan as an independent predictor of pulmonary function parameters: validation and reference values. Respirology 2007; 12: 361-6.

[18] Temple WP, Moris JF, Koski A. Prediction of normal spirometric values for adults incapable of standing. Chest 1988; 94: 572-4.

[19] Janssens JP, Pache JC, Nicod LP, et al. Physiological changes in respiratory function associated with ageing. Eur Respir J 1999; 13: 197-205.

[20] Riggs BL, Melton L. Involutional osteoporosis. N Engl J Med 1986; 314: 1676-86.

[21] Kjensli A, Ryg M, Falch JA, et al. Does body height reduction influence interpretation of lung function in COPD patients? Eur Respir J 2010; 36: 540-8.

(C) Ansari et al.; Licensee Bentham Open.

This is an open access article licensed under the terms of the Creative Commons Attribution Non-Commercial License (http://creativecommons.org/licenses/by-nc/3.0/) which permits unrestricted, non-commercial use, distribution and reproduction in any medium, provided the work is properly cited. 